\author{
Scientific Electronic Archives \\ Issue ID: Sci. Elec. Arch. Vol. 14 (10) \\ October 2021 \\ DOI: http://dx.doi.org/10.36560/141020211416 \\ Article link: https://sea.ufr.edu.br/SEA/article/view/1416
}

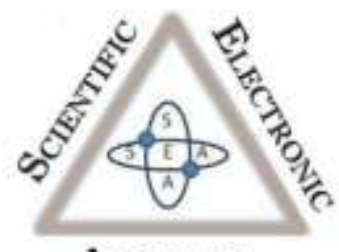

ArChives

ISSN 2316-9281

\title{
Relação das categorias de análise paisagem, território e lugar na construção de pequenas centrais hidrelétricas
}

\author{
Relation of the categories of analysis landscape, territory and place in the \\ construction of small hydropower plants
}

\author{
Corresponding author \\ Juliana Rodrigues da Silva \\ Universidade Federal de Mato Grosso \\ ju--silva@hotmail.com \\ José Roberto Tarifa \\ Universidade Federal de Mato Grosso
}

\begin{abstract}
Resumo. Com o crescimento populacional do Brasil no século $X X$, aliado ao rápido processo de industrialização, houve um aumento na demanda energética do país, surgindo a necessidade de novas fontes geradoras de energia, sendo as Pequenas Centrais Hidrelétricas (PCHs) uma dessas fontes. O presente estudo visou compreender, por meio da fundamentação teórica a relação das categorias de análise geográficas na construção das pchs. Na construção das pchs é importante o estudo das categorias de análise não de forma isolada, mas levando em consideração suas relações. A paisagem deve ser vista em torno de sua totalidade, levando em consideração os aspectos naturais, políticos, econômicos, sociais e culturais. Esses aspectos nos remetem ao território, em que nessas construções, não deve ser visto somente como uma delimitação das relações de poder, ou seja, além da dimensão material, deve levar em consideração a dimensão simbólica, construtora da identidade. É no lugar que essa identidade é intensificada, através dos laços afetivos, da experiência, das relações com os grupos sociais, pois o lugar em si não é visto somente como um local ou um ponto de referência situado no espaço, mas sim como um lugar de vivência, onde os laços serão criados e intensificados através da construção de sua identidade, e nesse lugar a apropriação e organização é de acordo com as necessidades de cada indivíduo. Assim, o modo de enxergar o mundo vai depender da percepção de cada sujeito, e como ocorre a sua relação com a natureza, nesse caso, transformando-a com a construção das pchs.

Palavras-chaves Energia; PCHs; Paisagem; Território; Lugar
\end{abstract}

\begin{abstract}
With the population growth in Brazil in the 20th century, allied to the rapid industrialization process, there was an increase in the country's energy demand, creating the need for new sources of energy generation, with Small Hydropower Plants (SHPs) being one of these sources. The present study aimed to understand, through the theoretical foundation, the relationship of the geographic analysis categories in the construction of the hydroelectric power plants. In the construction of the hydroelectric power stations it is important to study the categories of analysis not in isolation, but taking into account their relationships. The landscape should be seen around its totality, taking into consideration the natural, political, economic, social, and cultural aspects. These aspects bring us back to territory, which in these constructions, should not be seen only as a delimitation of power relations, i.e., besides the material dimension, it should take into consideration the symbolic dimension, a constructor of identity. It is in the place that this identity is intensified, through the affective ties, the experience, the relationships with social groups, because the place itself is not seen only as a place or a point of reference located in space, but as a place of living, where the ties will be created and intensified through the construction of identity, and in this place the appropriation and organization is according to the needs of each individual. Thus, the way of seeing the world will depend on the perception of each subject, and how his or her relationship with nature occurs, in this case, transforming it with the construction of the shps.
\end{abstract}

Keywords: Energy; SHPs; Landscape; Territory; Place

\section{Introdução \\ Com o crescimento populacional do Brasil \\ no século $X X$, aliado ao rápido processo de}

industrialização, houve um aumento na demanda energética do país, surgindo a necessidade de 
novas fontes geradoras de energia, sendo as pequenas centrais hidrelétricas uma dessas fontes.

Para atender e suprir essa demanda energética, o Brasil possui um total de 9.461 empreendimentos em operação, distribuídas pelas seguintes fontes geradoras: hídrica responsável por $62,16 \%$ do total produzido, sendo composta pelas usinas hidrelétricas $58,57 \%$, as pchs com 3,11\% e as centrais geradoras hidrelétricas $0,48 \%$; as termelétricas somam um total produzido de 24,40 $\%$; já a eólica produz 10,43\%; a fonte solar produz $1,87 \%$, e a nuclear é responsáveis por $1,13 \%$ da produção total de energia (ANEEL, 2021).

O grande potencial hídrico que o país possui, faz com que, essa fonte geradora seja a mais barata em relação as demais fontes. Apesar do seu baixo custo de construção e implantação, esse sistema desencadeia uma série de transformações locais e regionais, que afetam direta e indiretamente a vida.

Os impactos causados pela construção de Hidrelétricas e de pequenas centrais hidrelétricas são praticamente os mesmos, mas em proporções diferentes, uma vez que o tamanho da área afetada é diferente de acordo com o tipo de geração a ser instalada.

Independente de qual seja, hidrelétrica ou pchs, os impactos ultrapassam a noção de área diretamente afetada, pois provocam uma alteração biológica, econômica e social local ou até mesmo global.

As hidrelétricas fazem parte dos grandes projetos que contribuem para o ordenamento do território, já que determinam o fim e o surgimento de inúmeras cidades, vilas e povoados. Eles são uma forma de tentar influenciar, controlar objetos, pessoas e relacionamentos pela delimitação e afirmação de seu controle sobre uma área geográfica.

Com o represamento das pchs ocorre uma transformação na paisagem local, junto com a perda material e imaterial da população afetada. De acordo com Rolam e Campos (2014) essa transformação é resultante de processos naturais decorrentes da constante transformação da natureza, interagindo com processos sociais produzidos pelo homem que procura adequar a natureza a suas necessidades, e com isso, promover alterações drásticas no meio em que vive sendo algumas irrecuperáveis.

Essas mudanças alteram o sentido do lugar para as pessoas que nele vivem, pois nesse espaço, construíram sua identidade, suas relações de afetividade, que através da instalação e construção desses empreendimentos terão que se adaptar e começar uma nova vida.

Assim, partindo desse pressuposto 0 presente estudo visa compreender a relação das categorias de análise geográficas: paisagem, lugar e território, no estudo de construção das pchs.

\section{Contextualização e Análise}

\section{Paisagem}

A compreensão do significado da paisagem esteve relacionada a duas correntes de pensamento, a primeira ligada aos seus processos naturais, base para a Geografia Física, e a segunda voltada para a ação do homem sobre esses processos sustentada pela Geografia Humanística.

Por muitos é considerada como sendo somente o que a vista alcança, porém a paisagem vai além de nossa visão, ela apresenta características que não são percebidas através do olhar.

Ela apresenta partes estéticos particularmente visuais, porém está ligada a um universo cultural que ultrapassa os horizontes físicos do mundo natural, ou seja, a paisagem são os povos, os costumes, as atrações e repulsas, o modo de ser e muito mais, em síntese a paisagem é o cenário da vida e do cotidiano dos seres que povoam o espaço (EMIDIO, 2006).

Para Santos (2006) a paisagem existe através das formas criadas em momentos históricos diferentes, porém coexistindo com o atual, como resposta às necessidades atuais da sociedade.

Então a paisagem que era vista como um ambiente estático, passa a ser vista como um ambiente sujeito a alterações, ou seja, mutável, percebido de formas diferentes pelos sujeitos de acordo com suas necessidades.

Assim, a paisagem:

[...] não é a simples adição de elementos geográficos disparatados. É, em uma determinada porção do espaço, o resultado da combinação dinâmica, portanto instável, de elementos físicos, biológicos e antrópicos que, reagindo dialeticamente uns sobre os outros, fazem da paisagem um conjunto único e indissociável, em perpétua evolução (BERTRAND, 2004 p. 146).

A paisagem é construída e percebida por todos nós, cada pessoa possui um olhar, um comportamento, uma necessidade diferente, fazendo com que a paisagem seja sentida, percebida de forma singular.

Husserl (2001) afirma que o objeto (a paisagem) possui, para o sujeito que percebe, um conjunto aberto e infinito de possibilidades indeterminadas que não são, elas próprias, atualmente percebidas.

A paisagem é um signo, ou um conjunto de signos, que se trata então de aprender a decifrar, a decriptar, num esforço de interpretação que é um esforço de conhecimento, e que vai, portanto, além da fruição e da emoção (BESSE, 2006, p. 64).

A paisagem vista através da sua totalidade, levando-a em consideração como um todo, ou seja, o ambiente sujeito a ação do homem seja ele físico ou social, sofre reflexo em seu comportamento. É através do conjunto de formas (elementos naturais e culturais) que vão surgindo as heranças que nos 
mostram a relação entre o homem e natureza. Nessa relação o ser humano faz parte da natureza, assim como distingue-se e separa-se contextualmente dela através do intelecto e da razão, ele intervém no mundo natural modificando0 , enquanto que nesse processo ele também se modifica (COSGROVE, 1994).

\section{Território}

Desde sua origem, a noção de território esteve ligada ao território nacional, delimitado por fronteiras em que era exercido o poder pelo governo Partindo dessa perspectiva Gottmann (2012) entendo o território como:

[...] uma porção do espaço geográfico que coincide com a extensão espacial da jurisdição de um governo. Ele é o recipiente físico e o suporte do corpo político organizado sob uma estrutura de governo. [...] podemos, portanto, considerar o território como uma conexão ideal entre espaço e política. Uma vez que a distribuição territorial das várias formas de poder político se transformou profundamente ao longo da história, o território também serve como uma expressão dos relacionamentos entre tempo e política (GOTTMANN, 2012, p. 523).

Para Ratzel (1990) não se pode construir um Estado sem um território e fronteiras, como também por mais simples que seja a sociedade, só será possível sua construção junto com o território que lhe pertence.

O território é efetivado quando ocorre a manifestação e se exerce qualquer tipo de poder, de relações sociais, pois são estas que consubstanciam o poder e que os homens mantêm entre si na vida cotidiana, concluindo assim que, onde existem homens há relações e, têm-se, ao mesmo tempo, territórios (VALE et al, 2005, p. 16).

O território não se entende apenas como entorno físico onde se desenrola a vida humana, animal e vegetal e onde estão contidos os recursos materiais, mas compreende também a atividade do homem que modifica esse espaço (ALMEIDA; SOARES, 2009).

Ele não se caracteriza, exclusivamente, por um princípio material de apropriação, apresenta-se além da dimensão material, a dimensão simbólica, muitas das vezes construtora de identidade. Nesse sentido são os sujeitos que constroem o território, no seu processo de reprodução material e simbólica, historicamente, por meio da luta de classes condicionados pela lógica dinâmica e contraditória do modo de produção capitalista (CAMACHO, 2010, p. 76).

afirma que:

Partindo desse pressuposto, Haesbaert

[...] sempre e ao mesmo tempo, mas em diferentes graus de correspondência e intensidade, uma dimensão simbólica, cultural, através de uma identidade territorial atribuída pelos grupos sociais, como forma de 'controle simbólico' sobre o espaço onde vivem e uma dimensão mais concreta, de caráter político-disciplinar: a apropriação e ordenação do espaço como forma de domínio e disciplinarização dos indivíduos (HAESBAERT, 1997, p. 42).

Essa apropriação e ordenamento do espaço como forma de domínio nos remete ao pensamento de Ribeiro (1995) em relação aos empreendimentos, em que, uns privilegia e enobrece, fazendo-os donos da vida, e aos demais subjuga e degrada, como objeto de enriquecimento alheio. Santos; Silveira (2012) defende que, devemos ver entender a dinâmica territorial a partir da periodização, pois cada momento se caracteriza por diferentes formas de uso e apropriação do território marcadas por interesses particulares.

Assim:

[...] territórios são construídos (e desconstruídos) dentro de escalas temporais as mais diferentes: séculos, décadas, anos, meses ou dias; territórios podem ter um caráter permanente, mas também podem ter uma existência periódica, cíclica (SOUZA, 2008, p. 81).

Para Almeida e Soares (2009) as hidrelétricas fazem parte desses grandes projetos que contribuem para o ordenamento do território, já que determinam o fim e o surgimento de inúmeras cidades, vilas e povoados. Eles são uma forma de tentar influenciar, controlar objetos, pessoas e relacionamentos pela delimitação e afirmação de seu controle sobre uma área geográfica.

Nessa perspectiva Saquet; Antonello (2010) entendem que:

[...] o território é construído histórica e socialmente, por forças econômicas, políticas e culturais. Há um processo de apropriação do espaço, controle e dominação que gera certa formação territorial. [...] São agentes econômicos, políticos e culturais que traçam e concretizam estratégias de controle e dominação, influenciando as pessoas em suas ações e reações cotidianas (SAQUET; ANTONELLO, 2010, p. 407).

Os conflitos, as disputas, a busca pelo poder sofridas com o decorrer da evolução da humanidade nos remetem ao pensamento de Raffestin (1993), em que o espaço é a 'prisão original' que nos foi dado, já o território é a prisão que os homens constroem para si, em função de suas necessidades, e essas necessidades são para atender a uma minoria detentora do poder, e a maioria fica à mercê, tendo que se adaptar a esse território construído para uma elite.

\section{Lugar}

Para a Geografia Humanística que se apoia na fenomenologia e no existencialismo, o lugar parte do princípio da experiência, da afetividade, o sentimento de pertencimento que o indivíduo tem com o local. Assim o lugar terá significados diferentes para as pessoas que nele se encontram, pois sua percepção será por meio das relações 
efetivadas naquele espaço, sejam elas de compadrio, vizinhança, familiar, lazer, trabalho.

O lugar é o espaço vivido, isto é, a primeira relação com o mundo, onde se vive intensamente, se relaciona com as pessoas, e com o próprio espaço geográfico, enfim, é a primeira forma de contato com o mundo (CALLAI, 2004).

Nessa concepção o lugar deixa de ser somente um ponto de referência ou localização, e passa a ser um espaço onde ocorrem as mais profundas relações com o meio.

É um espaço construído como resultado da vida das pessoas, dos grupos que nele vivem, das formas de lazer, trabalho, produção e alimentação. É, portanto, cheio de histórias e marcas que trazem em si um pouco de cada um

O lugar é um mundo de significado organizado. É essencialmente um conceito estático. Se víssemos o mundo como processo, em constante mudança, não seríamos capazes de desenvolver nenhum sentido de lugar (TUAN, 1983, p.198).

Para Menestrino (2010), os lugares serão compreendidos como expressões do espaço, nos quais as vivências acontecem, especificando um modo de vida singular, demonstrando as relações sociais estabelecidas e as formas de organização espacial, através das relações de poder homem/natureza, que se traduzem em vínculos territoriais, como um modo de vida específico que se dão a partir deles.

A percepção é sempre percepção da coisa total, compreendida num campo mais amplo, o qual por sua vez, é abrangido em um horizonte de significados mais distantes (LUIJPEN, 1973).

De acordo com Santos (2005) as diferenças entre lugares são o resultado do arranjo espacial dos modos de produção e estes tornam-se concretos sobre uma base territorial historicamente determinada, pois leva em consideração as dimensões políticas, econômicas e sociais.

O lugar torna-se realidade, a partir da familiaridade e afetividade com o espaço, resultado da construção dos grupos que nele vivem. Com isso, o lugar só pode ser compreendido em suas referências, que não são específicas de uma função ou de uma forma, mas produzidos por um conjunto de sentidos, impressos pelo uso (CARLOS, 1996).

Para Tuan (1983), esse sentindo que atribuímos ao lugar, ocorre pela experiência, na qual por meio da sensação, percepção, emoção e concepção, conhecemos e construímos a realidade.

Mas sentir o lugar não é algo fácil e requer um certo tempo, pois esse sentir:

[...] se faz de experiências, em sua maior parte fugazes e pouco dramáticas, repetidas dia após dia e através dos anos. é uma mistura singular de vistas, sons e cheiros, uma harmonia ímpar de ritmos naturais e artificiais, como a hora do sol nascer e se pôr, de trabalhar e brincar (TUAN, 1983, p. 203).
Assim o local onde são instaladas as pchs possuem valores e significados diferentes. Para os ribeirinhos, que vivem e utilizam esse espaço como meio de produção e reprodução da vida social, há a construção de uma identidade única, com características especificas, que os definem.

Ao serem remanejados para outras áreas, terão que se adaptar e recomeçar a construção de novos laços, novas amizades, novas formas de produção, dessa forma construindo uma nova identidade.

\section{Energia elétrica e sua difusão no território brasileiro}

A disseminação do uso da energia elétrica no Brasil teve seu início de fato no século $X X$. Nesse período a região Sul e Sudeste passava por um crescimento acelerado da industrialização, que demandava cada vez mais energia, a crise do petróleo nos anos 70, foi o ponta pé para substituição da energia térmica pela hidroeletricidade. Dentre as soluções propostas, estão os projetos de engenharia na construção de barragens para a geração de energia.

O consumo de energia é utilizado como um indicador do desenvolvimento econômico e da qualidade de vida de qualquer sociedade, pois reflete o ritmo de atividade dos setores industrial, comercial, de serviços e a capacidade da população para adquirir bens e serviços tecnologicamente mais avançados (ANEEL, 2008).

A preocupação em relação a produção de energia por meio de fontes não renováveis, para atender e suprir a demanda energética com 0 processo de expansão do capitalismo, fez com que voltassem a atenção para a geração hidráulica, que até então era realizada somente para 0 abastecimento local, através de moinhos e rodas d'água. Esse cenário começa a mudar na década de 1920, em que "a geração hidráulica de energia já era majoritária nos Estados do Rio de Janeiro, São Paulo, Minas Gerais, Bahia, Goiás, Mato Grosso, Santa Catarina e Espírito Santo. O Estado de Minas Gerais foi o percursor na instalação de usinas hidrelétricas" (SANTOS E SILVEIRA, 2012).

A energia proveniente de hidrelétricas está entre aquelas com o menor custo de produção, sendo esse fator a explicação de sua expansão no Brasil, uma vez que, o país possui grande abundancia hídrica.

Nessa relação custo/benefício levando em consideração de acordo com Almeida e Soares (2009) "as áreas que passaram a ser alagadas, mudanças dos regimes hídricos dos rios, interferência no hábitat de inúmeras espécies nem sempre é quantificado e suficientemente mitigado".

Como alternativa para minimizar esse impacto gerado pela construção das usinas hidrelétricas, surge as pequenas centrais hidrelétricas, seu custo de implantação, operação e sua área de impacto é menor, porém não deixa de interferir e mudar tanto a paisagem como a vida local dos lugares em que são instaladas. 
Atualmente o Brasil possuem 425 pequenas centrais hidrelétricas em operação, estas correspondem a $3,11 \%$ do total de energia produzidas no país.

$\mathrm{Na}$ figura 1 é possível observar a distribuição das pchs pelo território brasileiro (ANEEL, 2021).

Além dessas em operação, o Brasil possui 25 pchs em fase de construção e 92 pchs, que não iniciaram suas obras. Juntas terão uma potência outorgada equivalente a 1,6 MW (ANEEL, 2021).

A região sul e sudeste, são as regiões com o maior número de pchs em operação atualmente no Brasil. Na região Centro-Oeste, o destaque é para o Estado de Mato Grosso, que detém 18,76 \% da capacidade de geração instalada, sendo também o estado com o maior número de pchs em operação do país (Figura 2).

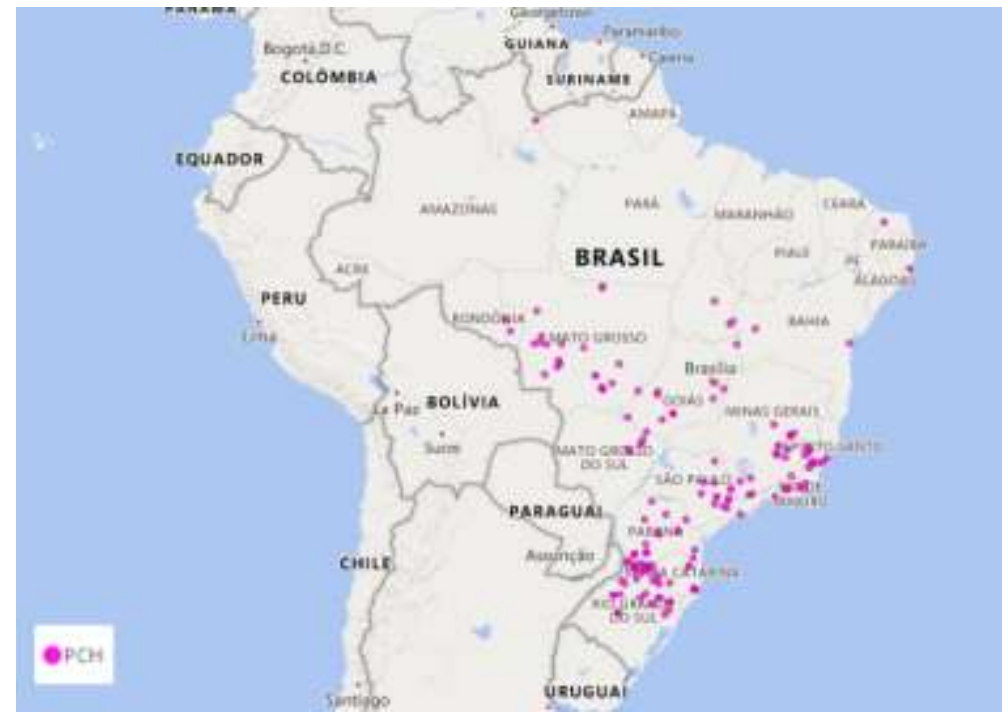

Figura 1: Pequenas Centrais Hidrelétricas em operação no Brasil no ano de 2021. Fonte: ANEEL, 2021.

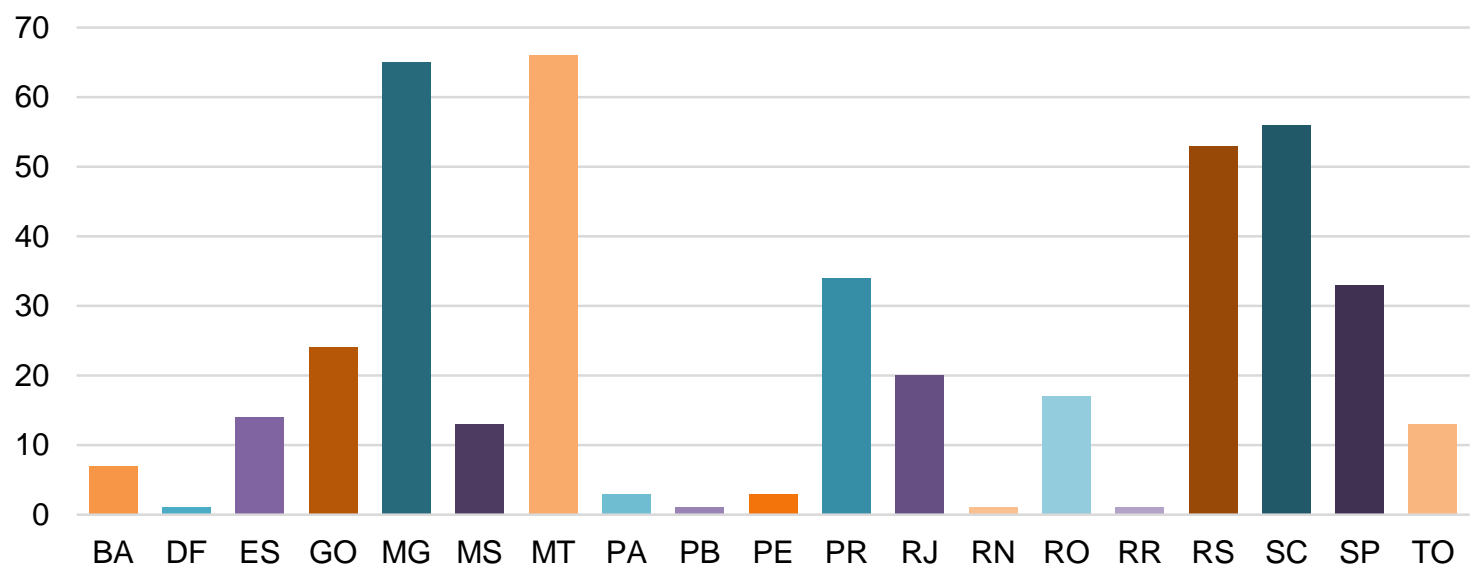

Figura 2: Distribuição das pequenas centrais hidrelétricas em operação por estado no Brasil em 2021. Fonte: ANEEL, 2021.

Relação entre paisagem, território e lugar no estudo para construção das pchs

Em decorrência do aumento na demanda energética do país, houve também, um aumento no número de empreendimentos para atender essa demanda.

As pequenas centrais hidrelétricas correspondem à uma dessas fontes que vem ganhando grandes proporções, sendo essas observadas em função do grande número de empreendimentos em operação e em fase de construção no Brasil.

A instalação das pchs resultam em uma alteração local, seja ela biológica, física, cultural, material ou social. Estudar e analisar a área em que serão instaladas e todas as alterações que poderão ocorrer não só local são cruciais, para elaboração dos processos de mitigação.

Assim a aplicação dos conceitos geográficos paisagem, território e lugar no estudo para construção das pchs, contribui especialmente 
para realização do diagnóstico socioeconômico dos locais em que esses empreendimentos serão instalados, uma vez que eles impactam e transformam tanto a natureza como a sociedade.
Na figura 3 é possível observar a relação entre as categorias de analise paisagem, lugar e território aplicadas no processo de construção das pchs.

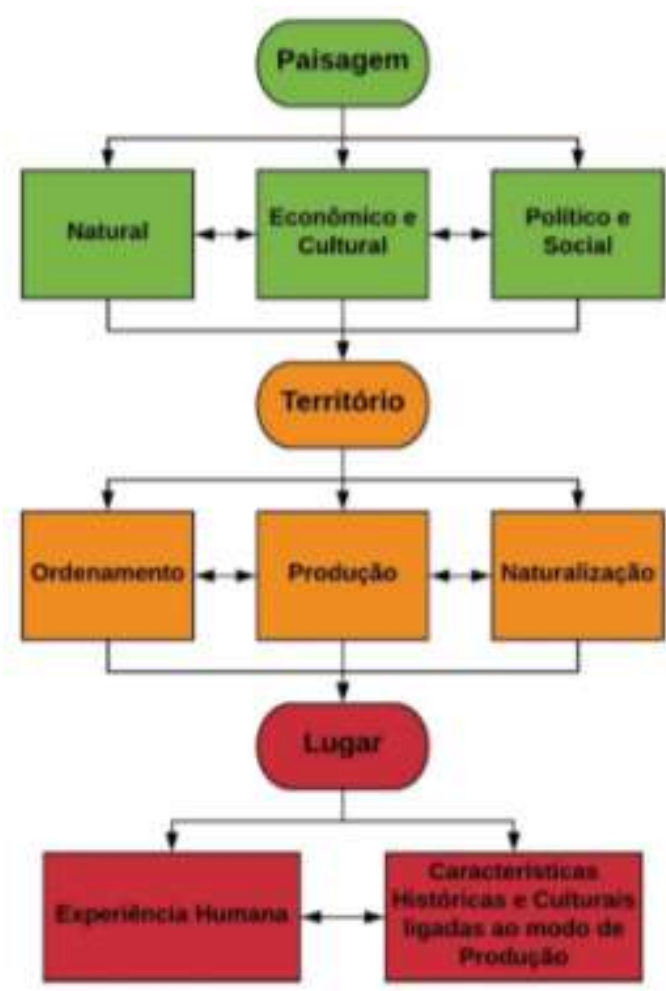

Figura 3. Relação das categorias de análise geográficas aplicadas no estudo das pchs. Fonte: MOREIRA, R. (2007), Org.: SILVA, J. R. (2019)

Seguindo essa relação, nos processos de construção e implantação das pchs, a paisagem não deve ser vista apenas pelos seus aspectos naturais como fauna, flora, relevo e potencial hídrico, mas sim em função de sua totalidade, levando também em consideração os aspectos econômicos, políticos, culturais e sociais do local afetado, e que poderão ser alterados ou até mesmo extinguidos.

Esse conjunto de fatores que compõem a paisagem, nos levam a formação do território, que por sua vez, não deve ser visto somente a partir das relações de poder político e econômico, mas devese levar em consideração os processos de ordenamento, produção e naturalização existentes, pois o desenvolvimento e a configuração local ocorreram utilizando os recursos existentes nessas áreas.

Com a construção dessas pchs, essas áreas sofrem um novo ordenamento territorial, e as pessoas afetadas, terão que se adaptar e modificar seu modo de produção, que antes eram feitos para atender suas necessidades e apoiadas nos recursos que essas áreas ofereciam.

Ao mesmo tempo que esse espaço é um território, é também um lugar, pois através das relações de ordenamento, naturalização e produção, do espaço, desenrola-se a vida humana em toda sua complexidade, criando uma identidade própria para as pessoas que ocupam essas áreas.

Esses processos afetam a vida local direta ou indiretamente, uma vez que seus indivíduos, terão que se adaptar à nova vida, uma nova área, um novo lugar. Na realidade um começar de novo, deixando para trás as ligações afetivas e sua identidade com seu espaço e grupo social.

O lugar carrega consigo, características históricas e culturais desses povos relacionadas ao modo de produção, é um local com uma riqueza imaterial incalculável, pois as experiências humanas, é algo que não tem preço.

\section{Considerações finais}

O Brasil passou por diversas transformações territorial até chegar na configuração atual. Essas transformações foram marcadas por resistências e conflitos, ligados a relação de poder político e econômico, transformando 0 espaço. Esse processo de construção e transformação do espaço pela apropriação do indivíduo, refletiu suas necessidades ao longo do tempo, adequando-o e criando suas relações com o lugar.

Assim as categorias de analise geográficas territórios, lugar e paisagem são temas crucial a 
serem abordados nos processos de construções de pchs, pois elas vão além das relações de poder político e econômico, levam em consideração o valor simbólico, os laços, as experiências de vida, a cultura, a forma de organização e apropriação do espaço onde serão realizadas essas obras.

Nos processos de implantação das pchs ocorrem mudanças: na paisagem que passa a ser vista como um ambiente sujeito a alterações mutáveis, percebida de formas diferentes pelos sujeitos de acordo com suas necessidades; da identidade, pois é no lugar que essa identidade é intensificada por meio dos laços afetivos, das experiências, das relações com os grupos sociais e do modo de vida das pessoas afetadas direta ou indiretamente por esses empreendimentos.

\section{Referencias}

ALMEIDA, F. G; SOARES, L. A. A. Ordenamento territorial: coletânea de textos com diferentes abordagens no contexto brasileiro. Rio de Janeiro: Bertand Brasil, 2009.

ANEEL - Agencia Nacional de Energia Elétrica. Matriz Elétrica Brasileira. Disponível em: < https://app.powerbi.com/view?r=eyJrljoiNjc4OGYyYj QtYWM2ZC00YjIILWJIYmEtYzdkNTQ1MTc1NjM2li widCI6ljQwZDZmOWI4LWVjYTctNDZhMi05MmQ0L WVhNGU5YzAxNzBIMSIsImMiOjR9> Acesso em 17 de junho de 2021.

ANEEL - Agencia Nacional de Energia Elétrica. Atlas de Energia Elétrica do Brasil. $3^{\circ}$ ed, Brasília, $2008 . \quad$ Disponível em: <http://www2.aneel.gov.br/arquivos/PDF/atlas3ed.pd f> Acesso em 03 de jul de 2019.

BERTRAND, G. Paisagem e Geografia física global: esboço metodológico. RA'E GA- Revista de Geografia da UFP, n. 8, p. 141-152, 2004.

BESSE, J. M. A Fisionomia da Paisagem, de Alexandre Von Humbold a Paul Vidal de La Blache. In: Ver a terra: seis ensaios sobre a paisagem e a geografia. Tradução Vladimir Bartalini. São Paulo: Perspectiva, 2006. p. 61-74.

CALLAI, H. C. O estudo do lugar como possibilidade de construção da identidade e pertencimento. 2004. Disponível em: <https://www.ces.uc.pt/lab2004/pdfs/HelenaCallai.pd f>. Acesso em 23 set. 2018.

CAMACHO, R. S. A produção do espaço e do território: as relações de trabalho subordinadas ao modo de produção capitalista. Entre-Lugar. v. 1, p. 73-98, 2010.

CARLOS, A. F. A. O Lugar no/do Mundo. São Paulo. Hucitec, 1996.

COSGROVE, D. (1994). Worlds of Meaning: Cultural Geography and Imagination. In: Re-Reading
Cultural Geography. (Orgs.) Foote, K. et al. Austin, The University of Texas Press.

EMIDIO, T. Meio Ambiente \& Paisagem. Ed. SenacSão Paulo, 2006.

GOTTMANN, J. A evolução do conceito de território. Campinas: Boletim Campineiro de Geografia, v. 2, no, pp. 523-545. 2012.

HAESBAERT, R. Des-territorialização e identidade: a rede "gaúcha" no Nordeste. Niterói: EDUF, 1997.

HUSSERL, E. (2001). Meditações Cartesianas: Introdução à fenomenologia (Oliveira, F., Trad.). São Paulo: Madras. (Originalmente publicado em 1931).

LUIJPEN, W. A. M. Introdução à Fenomenologia Existencial. São Paulo, EPU/EDUSP, 1973.

MENESTRINO, E. H. G. Povos tradicionais: do lugar ao não-lugar. 2010. Dissertação (Mestrado em Ciências do Ambiente) - UNIVERSIDADE FEDERAL DO TOCANTINS, Palmas.

MOREIRA, R. Pensar e ser em Geografia. São Paulo: Contexto, 2007.

RAFFESTIN, C. Por uma geografia do poder. São Paulo: Editora Ática, 1993.

RATZEL, F. Geografia do homem (Antropogeografia). In: MORAES, A. C. R. (Org.). Ratzel. São Paulo: Ática, 1990. p. 33-107

RIBEIRO, D. O Povo Brasileiro: evolução e o sentido do Brasil. São Paulo: Companhia das Letras, 1995.

ROLAM, V. A; CAMPOS, R. A. A Transformação da Paisagem no Espaço em que Vivo. 19 p. Artigo (Trabalho de Conclusão de Curso) Programa de Desenvolvimento da Educacional: UENP/SEED, 2014.

SANTOS, M. A natureza do espaço: técnica e tempo, razão e emoção. 4 ed. São Paulo: Edusp, 2006.

2005.

Da Totalidade ao Lugar. São Paulo, Edusp,

SANTOS, M; SILVEIRA, M. L. O Brasil: território e sociedade no início do século XXI. $16^{\circ}$ ed. Rio de Janeiro: Record, 2012.

SAQUET, M. A; ANTONELLO, J A. A territorialização na agricultura familiar: materializações na paisagem de Francisco Beltrão (Paraná, Brasil) In: anais V SIMPGEO (Simpósio Paranaense de Pós-Graduação e Pesquisa em Geografia). Curitiba, 2010, p. 405-420. 
SOUZA, M. L. O território: sobre espaço e poder, autonomia e desenvolvimento. In: CASTRO, I. E. et al (Orgs.). Geografia: conceitos e temas. Rio de Janeiro: Bertrand Brasil, 2008. p. 77-116.

TUAN, Yu-Fu. Espaço e Lugar: a perspectiva da experiência. São Paulo: DIFEL, 1983.
VALE, A. F; SAQUET, M. A; SANTOS, R. A. O território: diferentes abordagens e conceito-chave para a compreensão da migração. Revista Faz Ciência, Francisco Beltrão, PR, Universidade do Oeste do Paraná, v. 7, n. 1, p. 11-26, 2005. 